\title{
LOS PLATEROS DE LA CATEDRAL DE LIMA (1614-1663)
}

\author{
por RAFAel RAmOS Sosa
}

\begin{abstract}
El artículo reúne noticias documentales inéditas del archivo catedralicio sobre los plateros que trabajaron para el templo mayor de Lima. Se delimitan las funciones y salario del maestro platero de la Catedral así como las obras que realizaron para la Fábrica. Una importante característica de la plata peruana es la falta de marcaje. Hemos podido documentar que hacia 1617 las piezas debían de estar marcadas. Se citan en total 16 plateros casi desconocidos hasta ahora. Junto a la relación nominal de los artífices y los trabajos ejecutados se incluye un cuadro cronológico de los maestros plateros de la Catedral, otros plateros que trabajan para ella, tasadores y contraste.
\end{abstract}

This article contains previously unedited evidence from the archives of the silversmiths who worked for Lima Cathedral. The duties and salaries of the cathedral's master silversmith are defined, as are the works carried out for the Factory. A significant feature of Peruvian silver is the absence of hallmarks. We have established that pieces must have been marked from around 1617, and have also named sixteen silversmiths who were virtually unknown hitherto. A chronological chart of the cathedral's master silversmiths, other silversmiths who worked for it, valuers and assayers is included, along with a list of craftsmen and works carried out.

La platería virreinal ocupa un lugar importante en el arte del pueblo hispanoamericano, por la cantidad y calidad de las obras así como por los numerosos artistas, muchos de ellos casi desconocidos hasta ahora. No en vano, además, esta labor contaba con una arraigada tradición prehispánica. Los trabajos de la plata fueron un elemento indispensable en la vida del Antiguo Régimen como parte destacada del ornato de templos y casas, contribuía al esplendor y decoro 
de la liturgia y la fiesta, exponente de nobleza, poder y gusto suntuario de ciertos estatus sociales. Es sin duda un campo de ricos y variados valores que merecen atención y estudio ${ }^{1}$.

La historia del arte peruano se encuentra aún por hacer en muchas facetas. Quiero contribuir al conocimiento de la platería limeña con noticias parciales de los plateros de la Catedral de Lima.

Sin duda alguna, esta corporación tuvo una gran relevancia en el arte y sociedad de entonces. Prueba de ello es el crecido número de tiendas de platería a principios del siglo XVII que según el Padre Cappa eran ochenta, extendidas por las calles de Plateros, Plateros de San Agustín, Plateros de San Pedro y Callejón de Plateros (este último fue luego calle Petateros y hoy Pasaje Olaya, los otros son los actuales girones Ica y Ucayali).

Desde la fundación de la Ciudad de los Reyes en 1535 acudieron a establecerse artífices españoles y de otras partes de Europa. Estos plateros fundaron una primera cofradía de San Eloy, patrón del Arte, en una capilla de la iglesia de la Merced $^{2}$. No obstante en 1597, un grupo de plateros fundan de nuevo la Hermandad de San Eloy y Nuestra Señora de la Misericordia en la iglesia del convento de San Agustín con capilla propia. Dicha Hermandad redactó sus Constituciones que recogían sus actividades religiosas y de beneficencia, fueron aprobadas en $1622^{3}$.

1. Pueden consultarse las siguientes obras: MARQUEZ-MIRANDA, Fernando, Ensayo sobre los artífices de la Platería en el Buenos Aires Colonial, Buenos Aires, Imprenta de la Universidad, 1933. TORRE REVELLO, José, La orfebrería Colonial en Hispanoamérica y particularmente en Buenos Aires, Buenos Aires, Editorial Huarpes S.A., 1945. LAVALLE, José Antonio, Platería Virreinal, Lima, Banco de Crédito del Peru, 1974. ESTERAS MARTIN, Cristina, "Aportaciones a la H. ' de la platería cuzqueña en la segunda mitad del siglo XVII", en Anuario de Estudios Americanos, Sevilla, XXXVII, 1980; “Orfebrería Americana en Andalucía”, en Los Andaluces y América, Madrid, 1991. RIBERA, Adolfo L. y SCHENONE, Héctor H., Platería Sudamericana de los siglos XVI$X I X$, Hirmer Verlag München, 1981. SANZ SERRANO, M. Jesús, "La Platería Hispanoamericana. Estado de la cuestión", en VI Jornadas de Andalucía y América, Sevilla, 1986. HEREDIA MORE-

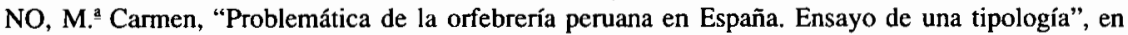
Príncipe de Viana, Pamplona, n.1 175, 1985; "Notas sobre plateros limeños de los siglos XVI-XVII (1535-1639)", en Laboratorio de Arte, Sevilla, n. 2, 1989.

2. HARTH-TERRE, Emilio, Artífices en el Virreinato del Perú, Lima, Torres Aguirre, 1945 , pág. 56.

3. TORRE REVELLO, José, El Gremio de Plateros en las Indias Occidentales, Buenos Aires, Imprenta de la Universidad, 1932, págs. 19 y ss., las Constituciones son reproducidas en el apéndice n. $\mathrm{8}$. Esta hermandad se nutría de los donativos y limosnas de los propios hermanos, pero parece que otra forma de obtener fondos para sus actividades benéficas era alquilar unas colgaduras para algunas festividades. Esta práctica también la realizaba la cofradía del Santísimo Sacramento de la Catedral de Lima y obtuvo cédula real el 10-9-1652 por la que se le otorgaba la exclusiva. La hermandad de San Eloy pidió autorización para continuar con esta práctica y la obtuvo por otra cédula del 28-111671, cfr. Archivo General de Indias, Lima 586, Libro I, ff. 288-291 v. 
Los plateros de la Catedral, durante el período de este estudio, tenían a su cargo el "aderezo", "reparo" y "limpieza" de toda la plata del templo mayor de la Ciudad de los Reyes. Su salario anual era de ciento veinte pesos de a ocho reales el peso, pagados en tercios. Fue más habitual el pago por el número de meses, en definitiva diez pesos al mes.

Parece que la tarea más frecuente trató de la limpieza de la plata. Esta labor suponemos que no tendría que ser realizada personalmente por el maestro platero sino que tal vez la efectuaría alguno de sus oficiales o aprendices del taller.

Aparte de este sueldo anual, si el cuidado de la plata suponía nuevas "hechuras" en las piezas, gasto del metal en cierta cantidad o realizar nuevas piezas, se le pagaba el importe de su trabajo además del sueldo. Estos trabajos lo podían hacer los maestros plateros de la Catedral o bien otros plateros contratados expresamente para esta tarea o encargo concreto. Por otro lado, fue frecuente que los trabajos de los plateros se presentaran adjuntando un memorial al Cabildo y otro platero nombrado por la Catedral tasada la obra. Si la pieza era de alguna envergadura se firmaba contrato ante escribano.

La tipología de las piezas que se menciona en la documentación es variada, tanto las que se reparan como las de nueva ejecución. Las más citadas son: vinajeras, candeleros, ciriales, blandones, incensarios, cruces de diversos tamaños y para distintos fines, sacras, corchetes (broches), lámparas, cetros, fuentes, salvillas, aguamaniles, patenas, relicarios, frontales de altar y alguna otra como el "rizo de plata" (especie de velo o puerta móvil del Sagrario). Todo este ajuar estaría inventariado y por iniciativa del Arzobispo se redactó en 1617 un nuevo inventario "de los bienes de la plata, oro, joyas y bienes" de la Catedral 4.

Una característica importante de la plata peruana es la falta de marcaje en las piezas que nos han llegado hasta hoy. No obstante parece que durante el siglo XVI y primera mitad del XVII debió de haberlas, pero piezas de esta época no nos han llegado pues muchas veces el sistema de trabajo y encargo de nuevas obras era a partir de las viejas que se fundían y volvían a realizar la pieza. Así por ejemplo en un memorial del platero Juan de Céspedes, fechado el 18 de marzo de 1617 dice que se gastó seis patacones en "el sello de acero para marcar la plata"s.

A continuación presentamos la relación nominal por orden alfabético de los plateros. Junto al nombre se apunta el tipo de platero que fue así como otro nombre con el que se cita en la documentación y las fechas extremas de sus distintos trabajos para la Catedral.

4. Archivo de la Catedral de Lima, Serie F. Libros de Cuentas de Fábrica, n. ${ }^{9}$ 2, f. 55. El 14-11617 se le pagaron 24 pesos al secretario del Cabildo, Cristóbal de Villanueva, por el "inventario nuevo".

5. Ibid., ff. 50-51. 


\section{Barragán, Luis (platero de mazonería) (1643-1646)}

En reunión del Cabildo del 12 de marzo de 1643 se acordó, dado que el platero Faustino de Escobar no enviaba a una persona que acudiera a limpiar la plata de la Catedral, que se diera el cargo al platero de mazonería Luis Barragán. El salario sería ciento veinte pesos pagados en tercios y con escritura ante notario. Se le hizo una primera paga de cuarenta pesos por cuatro meses de trabajo y luego un libramiento de trescientos pesos por el período desde el 12 de julio de 1643 a 29 de enero de $1646^{6}$.

\section{Bonifaz, Miguel (Miguel Bonifacio) (1618-1633)}

Este artífice fue platero de la Catedral desde noviembre de 1623. Aunque desde esta fecha hasta el 13 de mayo de 1631 se le pagaron doscientos treinta pesos de a ocho reales "por los aderezos en la plata blanca de la sacristía de esta Santa Iglesia", cantidad reducida teniendo en cuenta que son más de siete años. El 19 de junio de 1631 se le abonaron treinta patacones: ocho por cuatro pares de "corchetes grandes para las dos capas blancas ricas"; dieciséis por "emblanquecer los cuatro blandones grandes de la iglesia"; y seis por "emblandecer la lámpara del altar mayor". El 12 de enero de 1632 se le dieron ochenta pesos por su trabajo según una memoria y tasación del platero Diego González Chamorro. Otro pago de noventa patacones fue el 18 de septiembre de 1632 "de los adobios contenidos en la memoria retroescrita y de seis cañones de plata melcochados que hizo para la vara de la cruz que se lleva en las procesiones". Por último se le libró "de la plata que ha hecho nueva y aderezado y blanqueado" doscientos siete pesos el 23 de junio de 1633. Antes de ser platero de la Catedral también trabajó para ella el 6 de febrero de 1618 como tasador del trabajo del platero Juan de Céspedes ${ }^{7}$.

\section{Céspedes, Juan de (1616-1627)}

El 18 de marzo de 1617 presentó una relación al Cabildo "de las obras de aderezos de plata" que había hecho desde el 28 de junio de 1616. Sumaba un total de trescientos sesenta y cinco patacones pero el tasador, el platero Cristóbal Palomeque, la estimó en trescientos veintinueve patacones que es lo que se le pagó. En esta memoria se dice que, además de los trabajos de reparación y limpieza de distintas piezas, realizó unas vinajeras nuevas, dos incensarios a

6. Ibid., n. 9 3, ff. $742-744,750$ y 751 .

7. Ibid., n. .2 , ff. $71-72, n .93$, ff. $46,48,61,67$, y 717 . Parece ser que fue uno de los plateros que volvieron a fundar la hermandad de San Eloy en 1597, cfr. TORRE REVELLO, J. El Gremio..., apéndice n.. 8 . Un tal Bonifaz, que debe ser este, labra en 1627 una corona para la imagen titular del monasterio de la Concepción, cfr. VARGAS UGARTE, Rubén, Ensayo de un Diccionario de Artífices de la América Meridional, Burgos, 1968, pág. 176. 
partir de la plata de otros viejos y dos pares de ciriales, estos últimos por valor de ciento veinte patacones.

Poco después (quizá el 3 de abril de 1617) se le abonaron cuatrocientos cuarenta y ocho pesos y cuatro reales por la "hechura, plata y oro y esmaltes de la cruz nombrada guión" que iba delante del Cabildo Catedral en procesiones y demás actos en los que participaba. En una nueva memoria de su trabajo desde el 20 de marzo al 30 de diciembre de 1617 pedía ciento sesenta y tres patacones. Tasada su labor por el maestro platero Miguel Bonifaz se le libró ciento veinte pesos de a ocho reales. Sin ser ya el platero de la Catedral percibió el 31 de octubre de 1619, cincuenta pesos de a nueve reales por el "aderezo de la cruz de cristal y dorar la otra cruz de madera que dio el Señor Arzobispo don Gerónimo de Loaiza".

Por último sabemos que Juan de Céspedes efectuó una "cruz de plata para los entierros de los curas". A propósito de esta pieza debió de haber algún problema porque tuvieron que declarar sobre ella los plateros Diego de Requena y Benito Pereyra en 1627 y parece que Céspedes debía a Andrés de Mansilla ciento sesenta y seis pesos de a ocho reales "por la dicha cruz de plata" 8 .

\section{Díaz Galbán, Gerónimo (Gerónimo Galbán) (1654-1656)}

Este artífice fue el maestro platero de la Catedral al menos desde el 17 de enero de 1654 hasta el 11 de junio de 1656 en que fue despedido. Además de cobrar trescientos cincuenta pesos por su salario de este período de tiempo, hizo otros trabajos y algunas obras singulares como veremos. El 12 de mayo de 1654 se le abonan setenta pesos y medio "de aderezos de los blandoncillos de plata de la sacristía y la plata que puso para ellos y otros aderezos". El 13 de abril de 1655 se le pagaron doscientos siete pesos y medio por una salvilla, dos vinajeras $\mathrm{y}$ un aguamanil de plata dorada con sus cruces pequeñas. Todo por doce marcos y una onza a diecisiete pesos el marco 9 .

El domingo 19 de septiembre de 1649 se celebró en Lima una solemne procesión desde la iglesia del convento de San Francisco hasta la Catedral para trasladar la sagrada reliquia del Lignum Crucis que Urbano VIII regaló al templo mayor de la Ciudad de los Reyes ${ }^{10}$. En 1654 se encargó al arquitecto y escultor Mateo de Tovar un Sagrario de madera para guardar esta reliquia en la sacristía de la Catedral por valor de ciento cincuenta pesos. El Sagrario fue dorado por el

8 ACL, Serie F, Libros de cuentas de Fábrica, n. ${ }^{\circ}$ 2, ff. $50-52,71,72$ y $352 ;$ n. ${ }^{9} 3$, ff. 14-15. VARGAS UGARTE, R. o.c., pág. 187, dice que Juan de céspedes hizo dos atriles de plata en 1618 para la Catedral de Lima por valor de 1429 pesos.

9. ACL, Serie F, Libros de Cuentas de Fábrica, n.o 5, ff. 15, 221-226 y 323.

10. RAMOS SOSA, Rafael, La Fiesta y el Arte en Lima Virreinal (siglos XVI y XVII), Tesis Doctoral inédita, Universidad de Sevilla, 1991. 
maestro dorador Francisco Vázquez que cobró ciento diez pesos ${ }^{11}$. Parece ser que el Cabildo catedralicio acordó el 26 de junio de 1654 mandar hacer un "pie de plata... el mejor que se pudiere" para esta reliquia. El encargado fue Gerónimo Díaz Galbán que el 29 de diciembre de 1654 presentó una memoria o relación de lo que había costado "el relicario de plata dorada con sobrepuestos de oro... para poner el Santo Lignum Crucis". El peso del pie y relicario fue, según fe del contraste Pedro González, de trece marcos. El oro costó dieciséis pesos y la hechura de quince "sobrepuestos" de oro sesenta pesos. En total la obra costó quinientos sesenta y tres pesos y medio ${ }^{12}$.

\section{Escobar, Faustino de (platero de mazonería) (1636-1643)}

Es el platero que con certeza sabemos que trabajó durante estos siete años ininterrumpidamente con el sueldo habitual de diez pesos al mes. Comenzó su trabajo desde el 11 de marzo de 1636 y de él se decía que "ha limpiado con mucha curiosidad" la plata. El tesorero del Cabildo, doctor Juan de Cabrera, expuso el 12 de marzo de 1643 que Escobar "no ha dado persona que acuda a la limpieza de la plata y aderezo de la sacristía" y por ello se procedió a nombrar como platero de la Catedral a Luis Barragán ${ }^{13}$. Otros trabajos de Escobar fuera de salario fueron los siguientes. El uno de abril de 1637 expone una memoria con los arreglos hechos en la plata de la Catedral por valor de diez pesos y cuatro reales, tales como reparar un cetro, ponerle una chapa y un tornillo. En otra memoria del 7 de diciembre de 1627 se le pagan veinticuatro patacones: doce de hacer un nuevo cetro para el celador formado por cinco canutos, ocho nudetes, manzana y remate del cetro; tres por reparar la fuente grande dorada y nueve por "bruñir y dar color" a la cruz de cuatro brazos. El 1 de agosto de 1640 cobró ocho pesos por limpiar, bruñir y dar color a la cruz que sirve en las procesiones ${ }^{14}$.

\section{González, Pedro (contraste) (1654)}

Ver Gerónimo Díaz Galbán ${ }^{15}$.

\section{González Chamorro, Diego (tasador) (1632)}

Ver Miguel Bonifaz.

11. ACL, Serie F, Libros de Cuentas de Fábrica, n. ${ }^{2} 5$ ff. 319,325 y 327.

12. lbid., ff. 338 y 339 .

13. Ibid., n. 9 , ff. 724-743.

14. Ibid., ff. $746,747 \mathrm{y}$ el siguiente al $748 \mathrm{sin}$ foliar.

15. HARTH-TERRE, Emilio, "Un taller de platería en 1650", en Mercurio Peruano, n. 260, Lima, 1948, pág. 508, cita a un Pedro González por estos años, portugués de Punchal en las Islas Madera, que podría ser este mismo. 


\section{Gutiérrez Coronel, Francisco (tasador) (1636)}

Ver Francisco de Ribadeneira ${ }^{16}$.

\section{Ortiz Vizcaíno, Capitán Pedro (1656-1663)}

Por acuerdo del Cabildo el 11 de agosto de 1656 se le nombró platero de la Catedral en sustitución de Gerónimo Díaz Galbán desde el 11 de junio de ese año. Presentó algunas memorias con diversos trabajos pagados fuera de su salario anual. Así el 8 de junio de 1657 cobró veinte pesos por armar y desarmar en el altar mayor de la Catedral "el rizo de plata grande y frontal que se hizo para poner en él" el Santísimo Sacramento el día del Corpus y su octava. Otros veinte pesos fueron por limpiar estas piezas de plata ${ }^{17}$.

\section{Palomeque, Cristóbal (tasador) (1617)}

Ver Juan de Céspedes.

\section{Pereyra, Benito (tasador) (1627-1636)}

Ver Juan de Céspedes y Francisco de Ribadeneira ${ }^{18}$.

\section{Prieto, Francisco (maestro platero de plata) (1644)}

A este platero se le pagó el 9 de marzo de 1644, doscientos noventa y dos pesos de a ocho reales por unos blandones grandes que realizó a partir de plata vieja, con un peso total de ciento siete marcos de plata ${ }^{19}$.

\section{Requena, Diego de (maestro platero de plata) (1618-1647)}

Parece que fue el maestro platero que sucedió en el cargo a Juan de Céspedes desde el 1 de enero de 1618 hasta el 13 de septiembre de 1619. Se le pagaron ciento cincuenta pesos de a ocho reales por "hechura de la plata que ha hecho de nuevo... aderezar y limpiar la demás...". Intervino el 9 de enero de 1627 declarando junto con Benito Pereyra en el asunto de la cruz de plata realizada por Juan

16. Ibid., cita a Gutiérrez Coronel como originario de Extremadura, de la villa de Oropesa.

17. ACL, Serie F, Libros de Cuentas de Fábrica, n. ${ }^{\circ} 5$, ff. $226,229,369,376,405,411$ y 412 ; n. ${ }^{\circ}$ 6, ff. 38, 368, 369 y 378. HARTH-TERRE, E. “Un taller...", pág. 508, cita a un Pedro Ortiz, de Vizcaya.

18. HEREDIA MORENO, M. ${ }^{\circledR}$ Carmen, "Notas...", pág. 55, cita a Benito Pereyra como contraste del cabildo de la Ciudad entre el 13 de noviembre de 1626 y el 3 de enero de 1628. HARTHTERRE, E., "Un taller...", pág. 503 dice que Pereyra era maestro de hermosas custodias y relicarios, teniendo su casa junto a la recoleta de los padres dominicos. VARGAS UGARTE, R. o.c., pág. 325, nos dice que en 1642 intervino en la tasación de la plata labrada y otras joyas destinadas a la nueva fundación del convento de Carmelitas Descalzas de Lima.

19. ACL, Serie F, Libros de Cuentas de Fábrica n. ํ 3, f. 749. 
de Céspedes. Por último fue tasador el 23 de marzo de 1647 del trabajo de unos ciriales labrados por el platero Juan de Rueda ${ }^{20}$.

\section{Ribadeneira, Francisco de (platero de mazonería) (1628-1636)}

Su primer trabajo para la Catedral son unos blandones por los que se le abonan el 28 de febrero de 1628 , ciento ochenta y dos pesos y dos reales de ocho al peso como parte final del coste de la obra. Fue el platero de la Catedral desde el 5 de octubre de 1633 hasta principios de 1636 en que muere, pues el 11 de marzo de este año le releva el platero Faustino de Escobar. Además de limpiar y arreglar las piezas de plata del ajuar del templo realizó unos incensarios nuevos a partir de otros viejos. Así mismo los plateros Benito Pereyra y Francisco Gutiérrez Coronel tasaron un trabajo suyo que consistió en dar color, redorar y bruñir tres cruces: una grande por cincuenta pesos, otra mediana por veinte pesos y una pequeña de cristal por diez pesos. A su muerte, su viuda, Ana Gómez cobró veinticinco pesos que se le debían ${ }^{21}$.

\section{Rueda, Juan de (1639-1648)}

El 2 de diciembre de 1639 se le pagaron noventa y cinco patacones y seis reales que se le debían de un total de trescientos once por realizar seis cetros de plata a partir de otros viejos. El 12 de junio de 1645 se le pagaron setenta y un pesos y dos reales de a ocho el peso por un cetro estriado de plata para el pertiguero. También realizó unos ciriales nuevos con la plata de otros viejos que no se los habían pagado según petición del 15 de abril de 1645. Este trabajo fue tasado por Diego de Requena y se le abonó ciento veintinueve pesos dos años después. Creo que debió de ser el maestro platero de la catedral desde el 12 de febrero de 1646, pues desde esta fecha hasta el 12 de julio de 1648, el que recibía el dinero por la limpieza de la plata era el sacristán mayor de la Catedral, Gerónimo de Acevedo. En uno de los pagos se explica que el tal Acevedo pagó a Rueda "que es la persona que ha limpiado la plata de la sacristía" 22.

20. Ibid., n. 2 , f. 317 ; n..$^{\circ}$, f. 14 y 754 . Un platero del mismo nombre estuvo presente en la fundación de la hermandad de San Eloy en la iglesia de San Agustín en 1597, si se trata de la misma persona sería ya de edad avanzada, cfr. TORRE REVELLO, J., El Gremio..., apéndice n.9 8. VARGAS UGARTE, R., o.c., pág. 330, dice que junto con Francisco de Ribadeneira fue tasador de la plata del convento de Santa Catalina de Lima en 1630.

21. ACL, Serie F, Libros de cuentas de Fábrica, n. ${ }^{\circ}$, ff. 21,718 y 723 . Parece ser que también estuvo presente en la refundación de la hermandad de San Eloy en 1597, cfr. TORRE REVELLO, J., El Gremio..., apéndice n. ${ }^{\circ}$. Intervino en la tasación de la plata del convento de Santa Catalina de Lima en 1630 y el 17-8-1621 se obligó a realizar dos blandones de plata para la Catedral de Lima de 100 marcos cada uno, cfr. VARGAS UGARTE, R., o.c., págs. 330 y 333.

22. ACL, Serie F, Libros de Cuentas de Fábrica, n. 3 , ff. 294, 748 y 752-757. Según HARTHTERRE, E., “Un taller...”, pág. 508, este platero era de Huamanga. VARGAS UGARTE, R., o.c., pág. 503, lo cita como platero del XVII pero sin dar noticia alguna. 


\section{Ruiz Barragán, Antonio (1614)}

Tan sólo tenemos de él la noticia de un trabajo para la Catedral. Se le pagaron ochenta patacones "en que se concertó el aderezo que hizo de las palabras de la consagración de plata de la dicha iglesia y el oro que puso en dorarlas y esmaltarlas con orden de su Señoría Ilustrísima" ${ }^{23}$.

23. ACL, Serie F, Libros de Cuentas de Fábrica, n. ${ }^{2} 2$, f. 398 . Este platero fue otro de los fundadores y mayordomo de la hermandad de San Eloy en 1597, cfr. HARTH-TERRE, E., "Un taller...", pág. 507 y TORRE REVELLO, J. El Gremio..., apéndice n. 8. VARGAS UGARTE, R., o.c., pág. 340 y 458 dice que era platero de oro con caudal de 10.000 pesos. En marzo de 1603 pidió se hiciese información sobre él y ser nombrado balanzario y ensayador real. Murió en 1633 y en sus honras fúnebres, el 18 de julio de este año, predicó el obispo de Tucumán, Melchor de Maldonado y Saavedra, cfr. TORRE REVELLO, J.. La orfebreria..., pág. 58. 


\section{CUADRO CRONOLOGICO DE LOS PLATEROS DE LA CATEDRAL DE LIMA}

\begin{tabular}{|c|c|c|c|}
\hline $\begin{array}{c}\text { * Maestros plateros } \\
\text { de la Catedral }\end{array}$ & $\begin{array}{l}* * \text { Otros plateros que } \\
\text { trabajan para la Catedral }\end{array}$ & ** Tasadores & Contraste \\
\hline & $\begin{array}{c}\text { Antonio Ruiz Barragán } \\
13-11-1614\end{array}$ & & \\
\hline $\begin{array}{c}\text { Juan de Céspedes } \\
28-6-1616 / 30-12-1617\end{array}$ & & $\begin{array}{c}\text { Cristóbal Palomeque } \\
\text { 18-3-1617 } \\
\text { Miguel Bonifaz } \\
\text { 6-2-1618 }\end{array}$ & \\
\hline $\begin{array}{c}\text { Diego de Requena } \\
1-1-1618 / 13-9-1619\end{array}$ & $\begin{array}{c}\text { Juan de Céspedes } \\
31-10-1619\end{array}$ & & \\
\hline $\begin{array}{l}\text { Miguel Bonifaz } \\
1623 / 23-6-1633\end{array}$ & $\begin{array}{c}\text { Juan de Céspedes } \\
\text { 9-1-1627 } \\
\text { Fco. de Ribadeneira } \\
\text { 28-2-1628 }\end{array}$ & $\begin{array}{c}\text { Diego de Requena } \\
\text { Benito Pereyra } \\
9-1-1627 \\
\text { Diego González Chamorro } \\
\text { 12-1-1632 }\end{array}$ & \\
\hline $\begin{array}{l}\text { Francisco de Ribadeneira } \\
5-10-1633 / 1636\end{array}$ & & $\begin{array}{c}\text { Benito Pereyra y } \\
\text { Francisco Gutiérrez } \\
\text { Coronel 13-6-1636 }\end{array}$ & \\
\hline $\begin{array}{l}\text { Faustino de Escobar } \\
11-3-1636 / 12-3-1643\end{array}$ & $\begin{array}{l}\text { Juan de Rueda } \\
\text { 2-12-1639 }\end{array}$ & & \\
\hline $\begin{array}{l}\text { Luis Barragán } \\
\text { 12-3-1643/29-1-1646 }\end{array}$ & $\begin{array}{c}\text { Francisco Prieto } \\
9-3-1644 \\
\text { Juan de Rueda } \\
15-4-1645 \text { y } 12-6-1645\end{array}$ & & \\
\hline $\begin{array}{c}\text { Juan de Rueda } \\
12-2-1646 / 12-7-1648\end{array}$ & & $\begin{array}{c}\text { Diego de Requena } \\
23-3-1647\end{array}$ & \\
\hline $\begin{array}{l}\text { Gerónimo Díaz Galbán } \\
\text { 17-1-1654/11-6-1656 }\end{array}$ & & & $\begin{array}{l}\text { Pedro González } \\
\text { 29-12-1654 }\end{array}$ \\
\hline $\begin{array}{c}\text { Pedro Ortiz Vizcaíno } \\
11-6-1656 / 1663\end{array}$ & & & \\
\hline
\end{tabular}

* Las fechas que acompañan a los maestros plateros son las que consta que ocupan el cargo de maestro platero de la Catedral.

** Las fechas que acompañan a los plateros son la del cobro del encargo o tasación de la obra. 